\title{
Turning the Crisis Into an Opportunity: Digital Health Strategies Deployed During the COVID-19 Outbreak
}

Pol Pérez Sust ${ }^{1}$, BSc, MSc; Oscar Solans ${ }^{1}$, MD, MSc; Joan Carles Fajardo ${ }^{1}$, BSc; Manuel Medina Peralta ${ }^{2}$, MD, MSc; Pepi Rodenas ${ }^{1}$, BSc; Jordi Gabaldà ${ }^{3}$, BSc, MSc; Luis Garcia Eroles ${ }^{1}$, MD, MSc; Adrià Comella ${ }^{1}$, MD, MBA; César Velasco Muñoz ${ }^{4}$, MD, MPH, PhD; Josuè Sallent Ribes ${ }^{5}, \mathrm{PhD}$; Rosa Roma Monfa ${ }^{1}$, BSc, MBA; Jordi Piera-Jimenez ${ }^{6}$, $\mathrm{BSc}, \mathrm{MSc}$

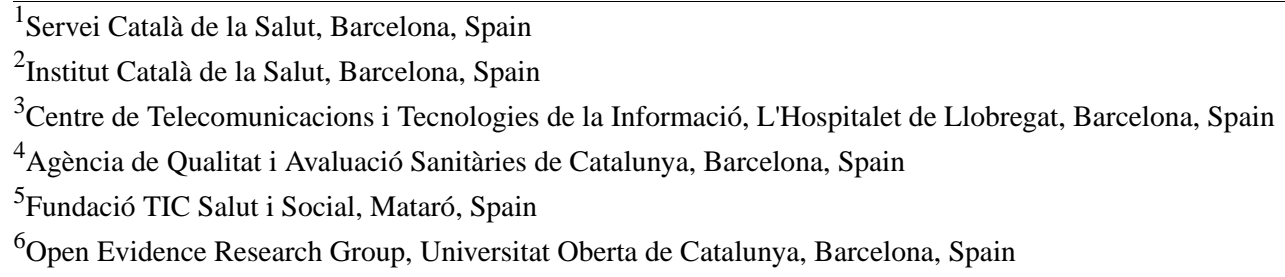

\section{Corresponding Author:}

Jordi Piera-Jimenez, BSc, MSc

Open Evidence Research Group

Universitat Oberta de Catalunya

Av del Tibidabo 39

Barcelona, 08035

Spain

Phone: 34651041515

Email: jpiera@bsa.cat

\section{Abstract}

Digital health technologies offer significant opportunities to reshape current health care systems. From the adoption of electronic medical records to mobile health apps and other disruptive technologies, digital health solutions have promised a better quality of care at a more sustainable cost. However, the widescale adoption of these solutions is lagging behind. The most adverse scenarios often provide an opportunity to develop and test the capacity of digital health technologies to increase the efficiency of health care systems. Catalonia (Northeast Spain) is one of the most advanced regions in terms of digital health adoption across Europe. The region has a long tradition of health information exchange in the public health care sector and is currently implementing an ambitious digital health strategy. In this viewpoint, we discuss the crucial role digital health solutions play during the coronavirus disease (COVID-19) pandemic to support public health policies. We also report on the strategies currently deployed at scale during the outbreak in Catalonia.

(JMIR Public Health Surveill 2020;6(2):e19106) doi: 10.2196/19106

\section{KEYWORDS}

digital health; eHealth; telemedicine; COVID-19; coronavirus; SARS-CoV-2; public health; policymaking

\section{Introduction}

Policymakers increasingly explore, accept, and apply information and communication technology (ICT) as part of health care systems. This shapes the way citizens and patients access and interact with the systems. The pathway to digital health (electronic health or eHealth) is a cultural transformation of the traditional construct of health care that encompasses multiple features, including widespread access to electronic health records, remote monitoring solutions, patient portals, wearable technologies, mobile health apps, data analytics, as well as other disruptive technologies [1].

For years, eHealth solutions have raised expectations on the cost savings associated with a reduction in travel to health care facilities and prevention of unplanned admissions due to regular check-ups [2]. In the last decade, the health care ecosystem has remarkably progressed in this direction; however, the multilevel complexity of eHealth implementation [3] is holding back the widespread use of ICT in routine practice [4]. 
With roughly 7.5 million inhabitants, Catalonia (Northeast Spain) has been considered a forerunner of eHealth adoption in Europe. Since 2009, a robust information exchange deployment has allowed health care providers within the public health system to share clinical information [5-7]. Currently, the region is implementing a comprehensive digital strategy-it is just one of the few ambitious initiatives that is transforming health information systems in Europe [7,8].

Worldwide, Spain is one of the most affected countries by the coronavirus disease (COVID-19) outbreak [9]. As of April 30, 2020, confirmed cases and deaths in Catalonia amounted to 54,324 and 5897, respectively. However, mathematical models predict a worsening of this scenario in the forthcoming days, which may lead to the saturation of the health care system due to the lack of intensive care specialists and complete occupation of intensive care unit (ICU) beds [10].
While clinical staff remains at the frontline to protect citizens from the pandemic, nonclinical actors like engineers, bioengineers, data scientists, and other ICT-related professionals are now taking the lead in fighting intensively to slow down the infection rate by deploying digital health solutions. In this context, the deployment of eHealth plays a major role in supporting public health policy $[11,12]$.

The objective of this viewpoint is to present the eHealth strategies adopted by the Catalonian Department of Health and the Catalan Health Service. These strategies aimed to avoid nonessential patient contact with the health care system and to improve control and diagnosis of COVID-19 (see Figure 1 for a detailed timeline). We report on the different strategies, the main objectives they are targeting, and the impact on stakeholders (Table 1).

Figure 1. Timeline of the digital health strategies deployed in Catalonia since the onset of the coronavirus disease (COVID-19) outbreak. eHealth: electronic health; GP: general practitioner.

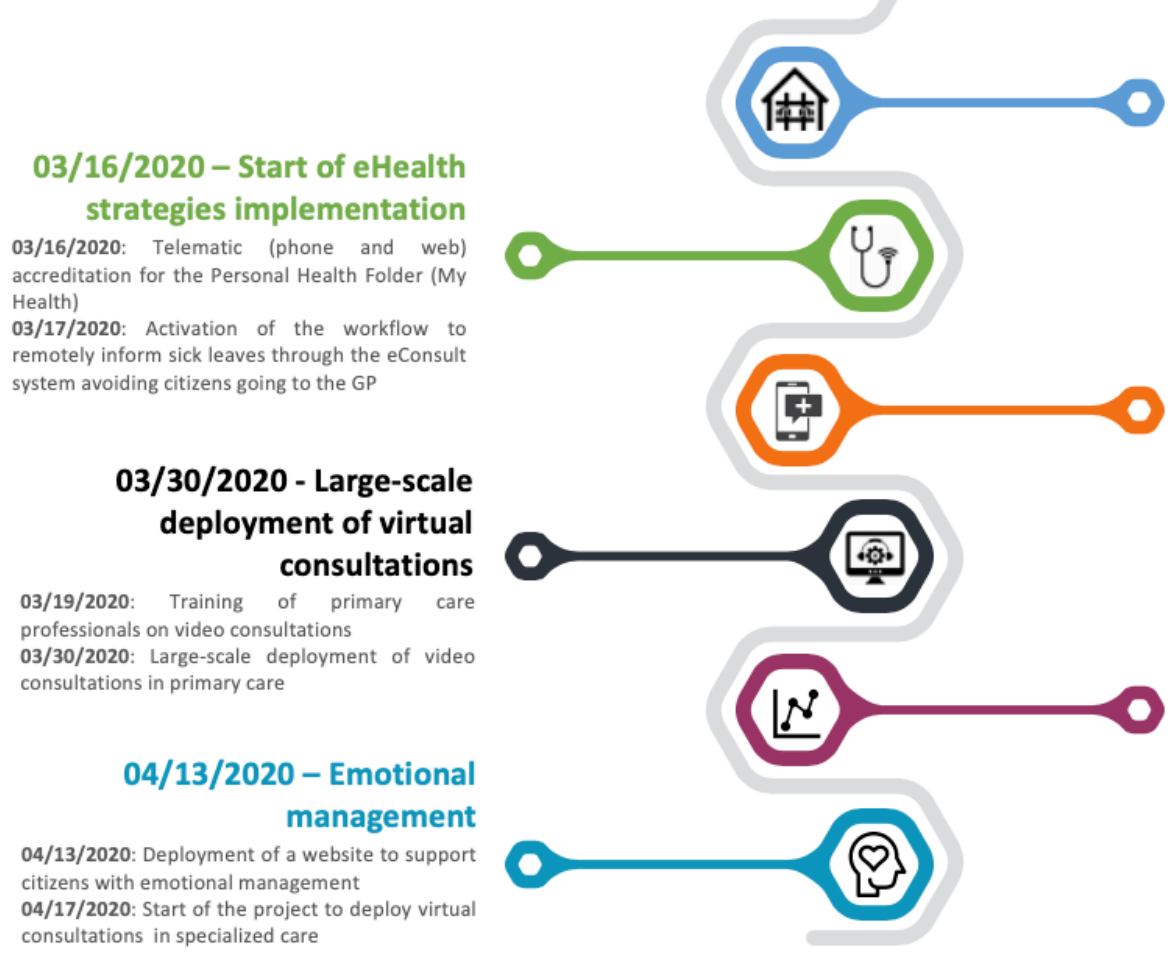

03/15/2020 - State of alarm 03/12/2020: The Catalan government declares the confinement of the population in Òdena valley 03/13/2020: The Catalan government declares the confinement of the entire Catalonian population and stop teaching activities 03/15/2020: The Spanish government declares the state of alarm

\section{3/18/2020 - Launch of mobile} health solutions

03/18/2020: Launch of the STOP COVID-19 CAT mobile app for self-assessment of symptoms of COVID-19

03/18/2020: Virtualization of the Electronic Medical Record systems for remote access (webbased technology) used at new health facilities and for telework

\section{4/03/2020 - Advanced data} analytics

04/01/2020: Deployment of a natural language processing algorithm to process all discharge reports (emergencies and hospitalization) to explore predisposing factors and noncoded positive cases 
Table 1. List of digital health strategies implemented during the coronavirus disease (COVID-19) outbreak in Catalonia.

\begin{tabular}{|c|c|c|}
\hline Strategy & Aims and expected benefits & Impact on stakeholders \\
\hline $\begin{array}{l}\text { 1. Facilitation of citizens' registration on the } \\
\text { Catalan Personal Health Folder ("My } \\
\text { Health") [13] by creating a specific call center } \\
\text { and enabling a webform for self-registration }\end{array}$ & $\begin{array}{l}\text { Establish a formal and secure communication } \\
\text { channel between the citizen and the health } \\
\text { care professional } \\
\text { - Decrease nonessential visits to health centers } \\
\text { by citizens } \\
\text { - Reduce infection risk for both citizens and } \\
\text { health care professionals }\end{array}$ & $\begin{array}{l}\text { - Citizens: burden of getting used to a new } \\
\text { communication channel; reduction in face-to- } \\
\text { face visits } \\
\text { - Health care providers: change of care delivery } \\
\text { model (ie, organizational and technical work- } \\
\text { flows); training of clinical staff; change man- } \\
\text { agement (ie, attitudes of reluctant profession- } \\
\text { als) } \\
\text { Policymakers: new appointment management } \\
\text { system; cybersecurity management; guarantee- } \\
\text { ing equity on access }\end{array}$ \\
\hline
\end{tabular}

2. Expansion of the virtual visits system ("eConsult") [14] by allowing the physician to appoint a videoconferencing session with the patient directly from the patient's EMR ${ }^{\mathrm{a}}$ in both primary and specialized care
3. Development of a mobile health app for self-assessment of the disease (STOP COVID19 CAT) [15], which includes geolocation of patients

4. Enabling of web access to EMRs throughout virtualization technologies

5. Reduction of bureaucratic barriers in health care processes by (a) allowing patients to access their sick leave forms in their personal health folder ("My Health"); (b) allowing pharmacies to access medication plans through the electronic prescription system of Catalonia in order to reduce the burden of citizens and primary care centers; (c) automatically extending chronic medication plans (eg, oral anticoagulant therapy)

6. Reporting of the day-to-day status of patients in nursing homes (private and public) through web service technology
- Establish a synchronous and asynchronous communication channel between the citizen and the health care professional

- Decrease nonessential visits to health centers by citizens

- $\quad$ Reduce the infection risk for both citizens and health care professionals

- Avoid increases in waiting lists

- Ensure care continuity

- Avoid increase in stress in health care professionals due to not being able to attend to their patients
- Create a heat map of the most affected areas

- Stratify patients and proactively contact highrisk individuals (Emergency Services of Catalonia)

- $\quad$ Substitute for the lack of COVID-19 tests
- Citizens: burden of getting used to a new communication channel; reduction in face-toface visits

- Health care providers: change of care delivery model (including organizational and change management); training of clinical staff; adaptation to new technologies (ie, integration with new platforms and acquisition of new hardware such as webcams and headphones)

Policymakers: development of new technologies and design of new financing models (ie, recognition of virtual visits as a billable service)

- Citizens: burden of getting used to a new technological channel

- Policymakers: development of new technologies; definition of new service models; facilitate the acceptance and motivation of citizens for using the mobile health app

- Ensure that health care professionals who are working in external consultations can continue their work from home (telework) during the lockdown period

- $\quad$ Ensure a smooth deployment of EMRs in emergency facilities (eg, hotels and pavilions)

- Avoid increases in waiting lists

- Ensure care continuity

- Decrease nonessential visits to health centers by citizens

- $\quad$ Reduce the infection risk for both citizens and health care professionals

itizens: burden of getting used to a new communication channel; reduction in face-toface visits

- Policymakers: development of new technologies and organizational workflows within the health care ecosystem (ie, pharmacies)
- Ensure the availability of near real-time data to make informed decisions

- Identify nursing homes with a high concentration of COVID-19 diagnosed patients

- Ensure accurate planning of actions and allocation of resources (ie, new $\mathrm{ICU}^{\mathrm{b}}$ beds and isolation facilities)
Health care providers: development of new technologies (ie, integration with the National Health Service system)

Policymakers: development of new technologies and organizational workflows within the health care ecosystem (ie, nursing homes) 


\begin{tabular}{|c|c|c|}
\hline Strategy & Aims and expected benefits & Impact on stakeholders \\
\hline $\begin{array}{l}\text { 7. Use of data analysis techniques to: (a) } \\
\text { predict the necessary number of ICU beds to } \\
\text { prevent overburdening the health care system } \\
\text { (using predictive modeling techniques); (b) } \\
\text { automatically analyze emergency and hospi- } \\
\text { talization reports to explore predisposing } \\
\text { factors and noncoded positive cases (using } \\
\text { natural language processing techniques) }\end{array}$ & $\begin{array}{l}\text { Avoid the collapse of the health system due } \\
\text { to a lack of hospitalization and ICU beds } \\
\text { Ensure accurate planning of actions and allo- } \\
\text { cation of resources } \\
\text { Enable research to advance the knowledge } \\
\text { of the disease }\end{array}$ & $\begin{array}{l}\text { Policymakers: development of new technolo- } \\
\text { gies; incorporation of new professional roles } \\
\text { (ie, data scientists) }\end{array}$ \\
\hline $\begin{array}{l}\text { 8. Management of the emotional status of } \\
\text { citizens by deploying a web portal ("Emotion- } \\
\text { al Management") [16] }\end{array}$ & 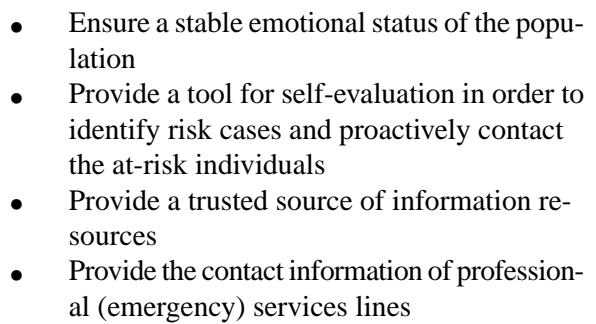 & $\begin{array}{l}\text { - Policymakers: development of new technolo- } \\
\text { gies and organizational workflows within the } \\
\text { health care ecosystem (ie, professional psychol- } \\
\text { ogy services) }\end{array}$ \\
\hline
\end{tabular}

${ }^{\mathrm{a} E M R}$ : electronic medical record.

${ }^{\mathrm{b}} \mathrm{ICU}$ : intensive care unit.

Preliminary results related to the implementation of the abovementioned strategies show a strong paradigm shift from face-to-face visits to virtual consultations in primary care. Figure 2 shows how face-to-face visits have reduced drastically since the start of the Catalonian lockdown on March 16, 2020. Face-to-face visits have been systematically replaced by both tele-consultations and eConsultations (electronic consultations), which present a sustained growth over the observed period.

Adoption of digital health technologies can also be observed in the increased number of visits to and new registrations on the Catalan Personal Health Folder. Table 2 shows the development of metrics between April 2019 and April 2020 (up to April 20, 2020). In March and April 2020, the records clearly exceed the annual average.

Even though Spain and Catalonia have now passed the peak of the COVID-19 outbreak at the time of writing [17], we continue to observe an increase in the adoption of the digital health solutions deployed by the Catalonian health care system. The present context indicates a continuation of the implementation processes. In fact, the current situation is unprecedented; many adoption barriers have disappeared while at the same time health care providers and professionals are demanding more and more technologies.

The COVID-19 pandemic has prompted a sudden turning point in the adoption of eHealth strategies in Catalonia. We expect that the changes we achieved over the last few weeks will be sustained even after the pandemic is over. 
Figure 2. Primary care visits compared to other care delivery methods in Catalonia for the period March 01, 2020, and April 19, 2020. Number of visits

160000

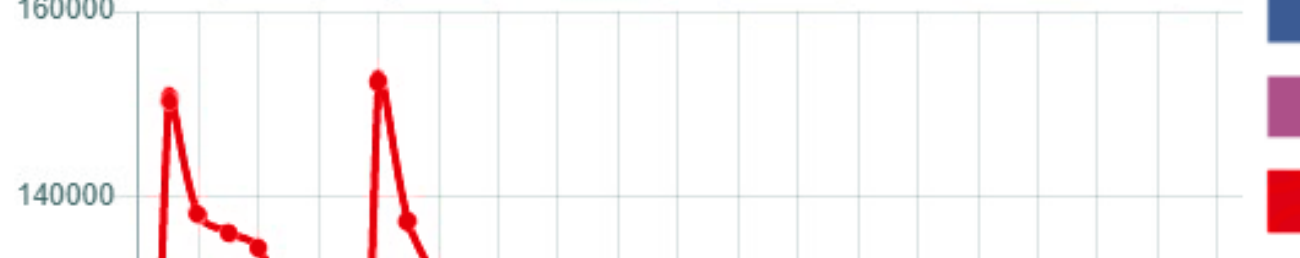

Tele-consultation

\section{Self-management}

120000

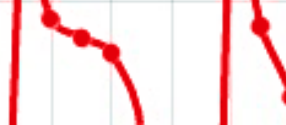

,

Face-to-face

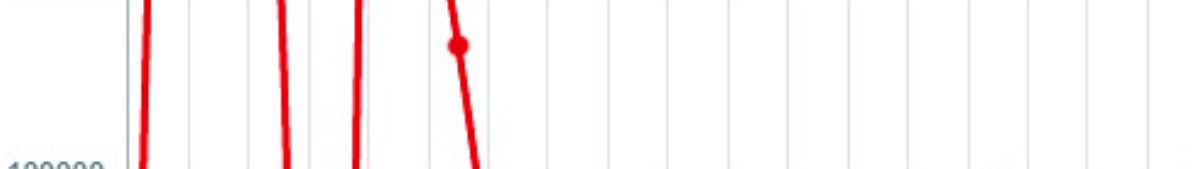

100000

80000

60000
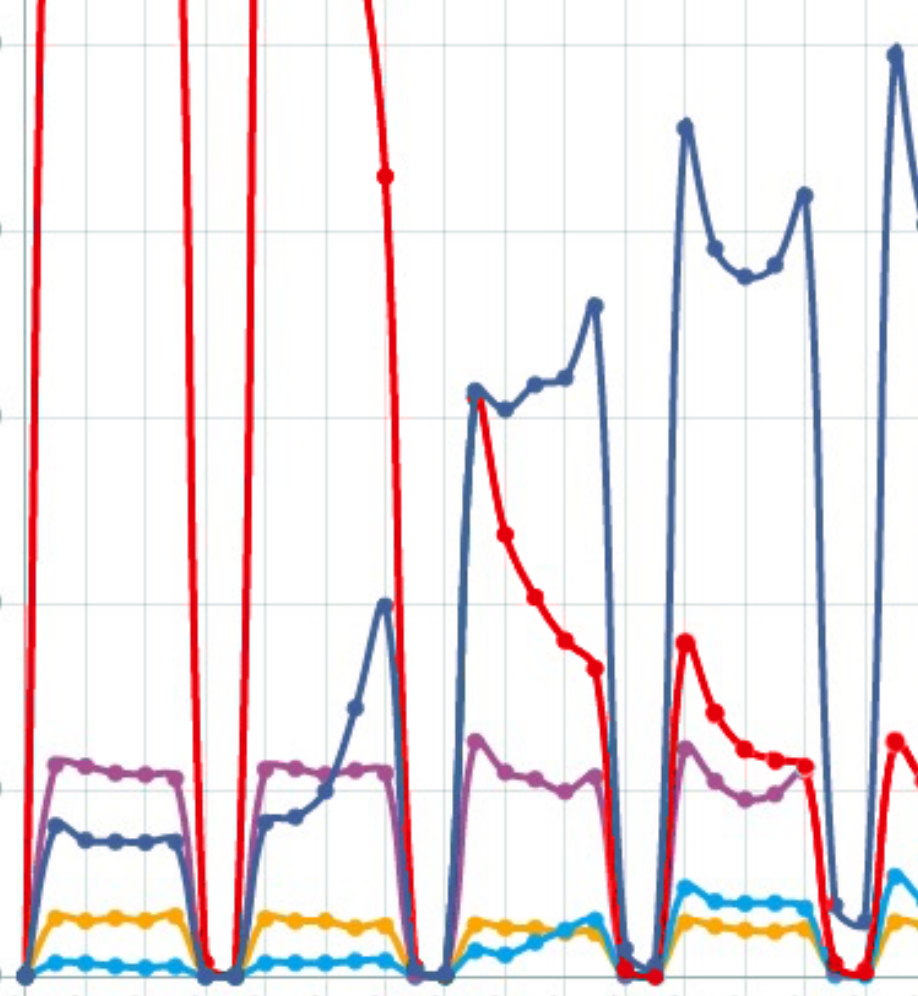

40000

(1)

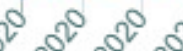
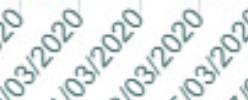

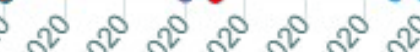

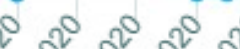

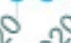

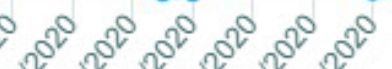

$\sqrt{10} 3^{3}$
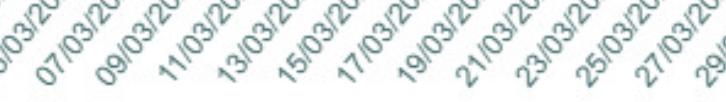
Table 2. Number of users who accessed the Catalan Personal Health Folder and new registrations for the period April 2019 to April 2020 (up to April 20, 2020).

\begin{tabular}{lll}
\hline Date & Users who accessed the Catalan Personal & New users, $\mathrm{n}$ \\
\hline April 2019 & Health Folder, $\mathrm{n}$ (19,026 \\
May 2019 & 280,001 & 20,400 \\
June 2019 & 323,035 & 15,798 \\
July 2019 & 293,691 & 18,002 \\
August 2019 & 319,622 & 12,475 \\
September 2019 & 292,248 & 16,547 \\
October 2019 & 303,754 & 21,699 \\
November 2019 & 376,081 & 20,220 \\
December 2019 & 353,523 & 16,022 \\
January 2020 & 319,021 & 19,434 \\
February 2020 & 384,290 & 21,397 \\
March 2020 & 390,836 & 52,698 \\
April 2020 & 649,992 & 48,862 \\
\hline
\end{tabular}

\section{Lessons Learned and Next Steps}

Below, we provide a list of lessons learned in the context of COVID-19 and future steps that should be taken:

1. The high pressure on the health care system in a situation of extreme crisis has been an outstanding driver of change. We analyzed the scenario to facilitate the adoption of eHealth technologies within our health system.

2. A long-term digital health strategy has proven to be the foundation for the accelerated change process. A good example of this is the unique EMR system we use in our primary health care system, which fostered the rollout of innovations faster than within a fragmented EMR ecosystem.

3. Having a very strong community and primary health care system has allowed us to implement different ICT strategies quickly by taking advantage of close interactions with the population.

4. ICT tools have been shown to be the main driver for decreasing health-related bureaucratic processes. This has allowed us to save professional staff time while avoiding nonessential visits by citizens to health centers and decreasing infection risks for both citizens and health care professionals.

5. No complaints against this comprehensive ICT deployment strategy have been received or noticed from health providers or citizens.
6. The deployment of ICT-enabled solutions should be accompanied by financial incentives for health providers in order to remove the financial barriers of adoption. Payment systems should adapt to facilitate easier ICT adoption.

7. Closer collaboration between health and social care services will be required in the future. The pandemic outbreak has shown us that coordination between both areas (ie, nursing homes and residential care) could be greatly improved by a stronger deployment of ICT (ie, access to primary care EMRs and/or deployment of telemonitoring solutions for residents).

8. We foresee many opportunities to further develop the virtual care model with more complex use case scenarios (ie, complex chronic needs). Current acceptance and need of ICT-enabled solutions has opened a window to further deploy the model in a system that has traditionally preferred face-to-face contact.

9. The ICT implementation may have avoided overcrowded health centers and, in consequence, lower infection and death rates. We need to further explore the impact of these deployments.

10. It is of outmost importance to assess how sustainable the adoption of the implemented digital health solutions on a long-term basis will be. We will continue monitoring the different implementation processes in order to assess use over time.

\section{Acknowledgments}

The authors would like to acknowledge the efforts of all Catalonian public servants during this global pandemic crisis. The authors would also like to thank Gerard Carot-Sans, PhD, Leah Bührmann, MSc, and Joan Carles Contel, MSc, for their critical review of the manuscript. 


\section{Authors' Contributions}

JP-J wrote the first draft of the paper. JP-J, PPS, AC, CVM, JSR, RRM, OS, PR, JCF, JG, MMP, and LGE revised the subsequent drafts critically for important intellectual content. All coauthors approved the final version of the manuscript. All authors agree to be accountable for all aspects of the work and for ensuring integrity and accuracy.

\section{Conflicts of Interest}

All authors are public servants involved in the deployment of the digital health strategies mentioned in this paper.

\section{References}

1. Meskó B, Drobni Z, Bényei E, Gergely B, Győrffy Z. Digital health is a cultural transformation of traditional healthcare. Mhealth 2017;3:38 [FREE Full text] [doi: 10.21037/mhealth.2017.08.07] [Medline: 29184890]

2. Alvarez RC. The promise of e-Health - a Canadian perspective. eHealth Int 2002 Sep 17;1(1):4 [FREE Full text] [doi: 10.1186/1476-3591-1-4] [Medline: 12459044]

3. Ross J, Stevenson F, Lau R, Murray E. Factors that influence the implementation of e-health: a systematic review of systematic reviews (an update). Implement Sci 2016 Oct 26;11(1):146 [FREE Full text] [doi: 10.1186/s13012-016-0510-7] [Medline: 27782832]

4. Baltaxe E, Czypionka T, Kraus M, Reiss M, Askildsen JE, Grenkovic R, et al. Digital Health Transformation of Integrated Care in Europe: Overarching Analysis of 17 Integrated Care Programs. J Med Internet Res 2019 Sep 26;21(9):e14956 [FREE Full text] [doi: 10.2196/14956] [Medline: 31573914]

5. Marimon-Suñol S, Rovira-Barberà M, Acedo-Anta M, Nozal-Baldajos MA, Guanyabens-Calvet J. [Shared electronic health record in Catalonia, Spain]. Med Clin (Barc) 2010 Feb;134 Suppl 1:45-48. [doi: 10.1016/S0025-7753(10)70009-9] [Medline: 20211353]

6. Solans O, Serra A, Hernandez S, Martinez J, Contel J, Olmedo I, et al. Health and social electronic records integratation in Catalonia. Int J Integr Care 2018 Oct 23;18(s2):76 [FREE Full text] [doi: 10.5334/ijic.s2076]

7. Catalan Department of Health. 2020. New Catalonian Digital Health Strategy: A Presentation URL: https://healthmanagement. org/uploads/article attachment/hm2-v20-journal-web-jordipierajim-nez-newcataloniandigitalhealth.pdf [accessed 2020-04-22]

8. Catalan Department of Health. 2018. Digital Health Strategy for Catalonia URL: https://pdsisbloggencat.files.wordpress.com/ 2018/02/pla director final v27.pdf [accessed 2020-04-22]

9. Legido-Quigley H, Mateos-García JT, Campos VR, Gea-Sánchez M, Muntaner C, McKee M. The resilience of the Spanish health system against the COVID-19 pandemic. The Lancet Public Health 2020 Mar. [doi: 10.1016/s2468-2667(20)30060-8]

10. Arenas A, Cota W, Gomez-Gardenes J, Gómez S, Granell C, Matamalas J. A mathematical model for the spatiotemporal epidemic spreading of COVID19. medRxiv Internet 2020 Mar 23 (forthcoming) [FREE Full text] [doi:

$10.1101 / 2020.03 .21 .20040022]$

11. Torous J, Jän Myrick K, Rauseo-Ricupero N, Firth J. Digital Mental Health and COVID-19: Using Technology Today to Accelerate the Curve on Access and Quality Tomorrow. JMIR Ment Health 2020 Mar 26;7(3):e18848 [ㅍREE Full text] [doi: 10.2196/18848] [Medline: $\underline{32213476]}$

12. Wind T, Rijkeboer M, Andersson G, Riper H. The COVID-19 pandemic: The 'black swan' for mental health care and a turning point for e-health. Internet Interv 2020 Apr;20:100317 [FREE Full text] [doi: 10.1016/j.invent.2020.100317] [Medline: $\underline{\text { 32289019] }}$

13. Catalan Department of Health. 2020. My Health URL: https://lamevasalut.gencat.cat/web/guest/pre-login-cps [accessed 2020-04-22]

14. Catalan Department of Health. 2020. eConsult URL: https://catsalut.gencat.cat/ca/serveis-sanitaris/la-meva-salut/econsulta/ index.html\#googtrans(ca|en) [accessed 2020-04-22]

15. Catalan Department of Health. 2020. STOP COVID19 CAT URL: http://canalsalut.gencat.cat/ca/salut-a-z/c/ coronavirus-2019-ncov/stop-covid19-cat/ [accessed 2020-04-22]

16. Catalan Department of Health. 2020. Emotional Management URL: https://gestioemocional.catsalut.cat/ [accessed 2020-04-22]

17. Lopez L, Rodo X. The end of the social confinement in Spain and the COVID-19 re-emergence risk. medRxiv Internet 2020 Apr 20 (forthcoming) [FREE Full text] [doi: 10.1101/2020.04.14.20064766]

\section{Abbreviations}

COVID-19: coronavirus disease

eConsultation: electronic consultation

eHealth: electronic health

EMR: electronic medical record

ICT: information and communication technology

ICU: intensive care unit 


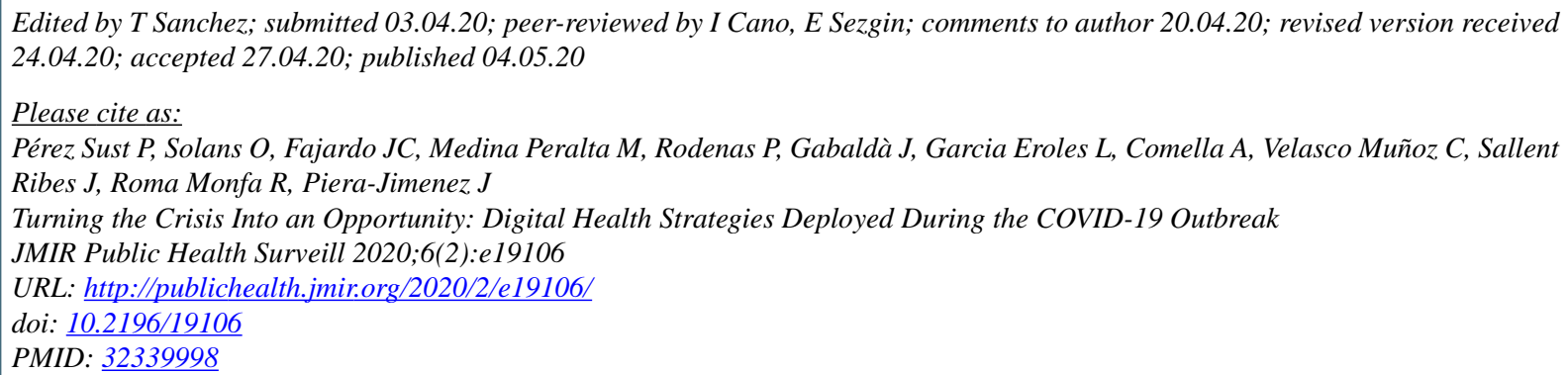

CPol Pérez Sust, Oscar Solans, Joan Carles Fajardo, Manuel Medina Peralta, Pepi Rodenas, Jordi Gabaldà, Luis Garcia Eroles, Adrià Comella, César Velasco Muñoz, Josuè Sallent Ribes, Rosa Roma Monfa, Jordi Piera-Jimenez. Originally published in JMIR Public Health and Surveillance (http://publichealth.jmir.org), 04.05.2020. This is an open-access article distributed under the terms of the Creative Commons Attribution License (https://creativecommons.org/licenses/by/4.0/), which permits unrestricted use, distribution, and reproduction in any medium, provided the original work, first published in JMIR Public Health and Surveillance, is properly cited. The complete bibliographic information, a link to the original publication on http://publichealth.jmir.org, as well as this copyright and license information must be included. 